\title{
For the Love of Darcie: Recognising the Human-Companion Animal Relationship in Housing Law and Policy
}

\author{
Deborah $\operatorname{Rook}^{1}$ (D)
}

Published online: 17 April 2018

(C) The Author(s) 2018

\begin{abstract}
This paper identifies the law's failure to recognise and protect the human-companion animal relationship in the housing arena. The nature of the human-companion animal relationship has striking similarities to human-human relationships in the socially supportive aspects of the relationship such as attachment, nurturance and reliable alliance. This contributes to the social life and sense of well-being of the owner. There is also evidence that the human-companion animal relationship can have physical health benefits such as lowering the risk of death by cardiovascular disease. It is clear that society benefits from the human-companion animal relationship, which many owners perceive as akin to family, in the form of healthier, less isolated people with better social networks. Yet in the key area of housing, the law does nothing to protect or even recognise this relationship. In consequence, every year thousands of tenants in both the public and private sector are faced with 'no pet' covenants in their leases and grapple with difficulties such as reduced housing options, higher rents or the traumatic decision to give up their companion animal for rehoming or euthanasia. This is especially prevalent amongst vulnerable people, like the elderly and mentally ill, who are more likely to need to move into supported accommodation. This article examines housing law in countries, such as France and Canada, that prohibit 'no pet' covenants in residential leases and provides arguments for the effective formulation and implementation of such law in the UK.
\end{abstract}

Keywords Human-companion animal relationship · Housing law • 'No pet' covenants $\cdot$ Companion animals $\cdot$ Pets $\cdot$ Human rights

Deborah Rook

debbie.rook@northumbria.ac.uk

1 School of Law, Northumbria University, Newcastle upon Tyne, UK 


\section{A Case Study: Bob and Darcie}

In April 2017 Bob, an 87 year old man from Scotland, left his residential care home after being threatened with eviction. He had been faced with a difficult choice-give up part of his family or give up his home. He chose, as many would, to keep his family together and leave his home. His family consisted of his companion animal, Darcie, a 10-year old Schnauzer dog whom Bob and his wife, Margaret, had taken into their lives and home as a puppy. To Bob, Darcie was part of the family and when Margaret died in 2014, Bob and Darcie became the only remaining members of the family unit. The strength of Bob's sentiment towards Darcie is displayed in his words "He means everything to me. Everything. He's my life now". ${ }^{1}$ Bob was forced to give up his home at the residential care home where he enjoyed the benefits of security, home support, meals and a sense of community with the other residents. For the love of Darcie, he gave all this up, and moved into private rental accommodation, based on the strength of the relationship he shared with his dog. A relationship that is currently ignored by housing law and policy.

This article argues that legislation is needed in the UK to prevent landlords of residential properties from banning pets. The article proposes using an existing legal concept, that of treating animals differently at law depending upon how we use them, as a precedent for treating animals differently depending on the nature of our relationship with the animal. The article examines the origin of the legal status of domestic animals as property in order to differentiate our relationship with companion animals from our relationship with other animals based on notions of trust and domination. The article then examines some of the beneficial effects of a close relationship with a companion animal on the health and social well-being of the owner. To better understand how housing laws in the UK could protect our relationship with companion animals, the article examines legislation in other jurisdictions that prohibits landlords from having 'no pet' covenants in residential leases. Finally the article examines human rights law. Relying on the social nature of the relationship with pets and the physical and psychological benefits flowing from this relationship, and using human rights case law from Belgium as an example, the article argues that the human-companion animal relationship falls within Article 8 of the European Convention of Human Rights and considers the implications of this on housing law and policy in the UK.

\section{The Human-Companion Animal Relationship}

The scholarly discipline of human-animal studies seeks to understand how animals are socially constructed. Once an animal is incorporated into the human social world, it is assigned a category, usually based on how it is used by humans.

\footnotetext{
1 Elderly people in struggle to keep pets in care homes, says charity. BBC news report, 9 January 2017. http://www.bbc.co.uk/news/av/uk-38553330/elderly-people-in-struggle-to-keep-pets-in-care-homes-sayscharity (accessed 2nd November 2017).
} 
This social category is more important than the biology of the animal in determining the status and treatment of the animal including at law (DeMello 2012). For example, a rabbit's biology classifies it as a member of the species Oryctalygus cuniculus, but the treatment of the rabbit under English Law depends upon its use: is it a pet rabbit? (protected by the Animal Welfare Act 2006); or a rabbit bred for meat? (in which case the Welfare of Farmed Animals (England) Regulations 2007 also apply); or is it a rabbit used in scientific procedures as an experimental test subject? (which would exclude the provisions of the Animal Welfare Act 2006 and instead apply the Animals (Scientific Procedures) Act 1986) or is it a wild rabbit? (which is deemed a pest and generally excluded from the protection of the law unless under the permanent or temporary control of a person). Consequently, it is the social category bestowed upon the rabbit that determines its treatment under the law. It is here suggested that this legal construct, of treating animals differently depending upon their use to humans, can be invoked to protect our relationship with companion animals. To do this, we first need to recognise the unique relationship humans share with their companion animals, which is akin to family (Serpell 1996; Franklin 2006; Charles and Aull Davies 2008). I use the word 'companion animal' to differentiate those animals kept primarily for social or emotional reasons from those kept primarily for economic or work purposes (Serpell and Paul 1994). The term also better reflects the change in our relationship with these animals over the last 50 years, for example, dogs used to sleep in a kennel outside the house rather than in the owner's bedroom. Franklin suggests that it was "after the 1970 s that 'pets' changed to 'companion animals", (Franklin 2006). I use the word 'family' tentatively, aware of its limitations just as others have done in the context of research on lesbian, gay and bisexual relationships. The rise of the LGBT community led to new forms of relationships and the concept of 'families we choose' (Weston 1991). In her article 'My Friends are my Family', Westwood observes, "We simply do not as yet have a vocabulary to describe these new relationship forms" (Westwood 2013) so she uses "friendship' in her article whilst recognising its limitations. Similarly, with companion animals we can observe the strength of the bond between an owner and an animal whilst acknowledging the limitations of labelling this relationship as family. This term is heavily laden with human associations and is not ideally suited for the unique relationship we share with companion animals but in the absence of alternative appropriate vocabulary, the terminology is borrowed with the caveat that companion animals are akin to family rather than being family. However, this distinction is undoubtedly very subtle and many owners, like Bob, will perceive their companion animal as a member of the family for everyday living purposes.

Westwood argues that for many people, particularly in later life, friendships can be the most significant relationships, more important than family relationships (Westwood 2013). Yet in key areas of law and social policy, such as welfare benefits and medical decision-making, friendship is not recognised by the law. She argues that the law needs to keep pace with changing relationship forms and considers how its failure to do so impacts on equality for older people. There are parallels here with the relationship people develop with their companion animal and the failure of the law to recognise this relationship in the important area of housing. 
Companion animals are deemed property at law. There is a mismatch between their legal status as property and the way in which people socially construct their companion animal as part of their family. To use Bob's words, Darcie is "my life". These are powerful words to describe a relationship that in law is classified as property. This divergence of law and reality has also been noted in the context of pet custody disputes that can arise following a separation or divorce of a couple where both parties want the family pet to live with them. The courts have struggled at times to apply pure property law tests given the strength of the bond between the human and the companion animal (Rook 2014). By understanding the origin of the legal status of domestic animals as property, it is possible to differentiate our relationship with companion animals from our relationship with other animals. Statistically, in the USA, farm animals represent $98 \%$ of all animals with whom we interact (Wolfson and Sullivan 2004) and it is likely to be a similar figure in England. Thus the majority of human-animal relationships rely on our ability to use animals for our own purposes with little, or no, benefit to the animal, for example, intensively farmed animals are generally denied a natural environment and are killed prematurely and animals used for scientific procedures can be subjected to pain and suffering. However, our relationship with companion animals, such as the cats and dogs living in our homes, is different. In most cases, the companion animals benefit from their relationship with us. We do not need to harm their welfare for our own benefit. On the contrary, we often reap social and health benefits from the very act of fulfilling the animal's welfare needs. This is unique in the human relationship with animals and justifies a unique approach in law, which both recognises and protects the human-companion animal relationship.

\section{The Origin of the Legal Status of Domestic Animals as Property}

In the history of our relationship with those animals that we eat there have been conflicts and contradictions, arising from our desire to use the animals as utilitarian objects whilst simultaneously recognising them as sentient beings capable of pain and suffering. By tracing the history of this conflict and exploring human defence mechanisms and coping strategies, developed over time to defuse or hide the conflict and assuage any feelings of guilt or discomfort, it is possible to understand the origin of the property status of companion animals and thereby highlight its inadequacies.

The origin of the legal status of domestic animals as property is thought to lie in the domestication of animals and the move from hunter-gatherers to pastoralists. The beginnings of livestock husbandry is dated approximately 9000 years ago starting with sheep and goats (Clutton-Brock 1994). However, our relationship with dogs is much older. The conventional view is that humans first domesticated their hunting partner, wild wolves, 10-20,000 years ago (Davis and Valla 1978; Beck and Katcher 1996), however some suggest that it was much earlier, approximately 100,000 years ago (Morell 1997). Using selective breeding to encourage the characteristics we desired-playfulness, subservience, dependence-dogs are the creation of humans. Beck and Katcher suggest "Our affection for dogs may simply be a way of expressing the love that a creator has for his or her creation" (1996: 171). They hypothesize 
that "the relationship between dogs and people is rooted in the evolution of both" (1996: 176). Given the long history we have with dogs, it is not surprising that dogs are our most popular companion animal and the animals with whom we develop some of our strongest bonds. ${ }^{2}$

Studies of pets in primitive societies hint at a significant paradigm shift as humans progressed from hunter-gatherers to agriculturists. Ingold adopted an indigenous perspective' to understand our domestication of animals that were once wild. He sought to shed the dichotomies of 'wild versus domestic' and 'nature versus humanity' traditionally used in the West to tell the story of the history of our relationship with animals, and instead sought to understand the nature of the relationship between hunter-gatherers and animals from the perspective of the indigenous people (Ingold 1994). From their perspective, the natural world is not separate from, and inferior to, the human world. It does not have to be conquered or controlled. Instead, animals are fellow inhabitants of the same world as humans. Serpell observes that there is much consistency in how hunter-gatherer societies view animals as rational, sentient and intelligent beings with spirits or souls that can survive the body after death (Serpell 2000). For example, the Cree Indians of Northern Canada believe that animals intentionally present themselves to the hunter to be killed and on death the soul of the animal is released to become flesh again (Tanner 1979; Ingold 1994). The hunter must be respectful and not wasteful or the animal will remember the transgression and not present itself in the future. This means that the success of the hunter depends on establishing a continuing relationship with the animals; a relationship, Ingold argues, based on trust. For him "The essence of trust is a peculiar combination of autonomy and dependency" (1994: 13). The hunter is dependent on the animal and takes a risk that the animal, as an autonomous being, will act in the interests of the hunter and present itself to be killed. In return, the hunter is respectful of the animal; but this egalitarian moral ideology was clearly incompatible with the shift to agriculture and the domestication of farm animals for meat. According to Ingold the relationship the pastoralist has with animals is based on domination not trust. The animals are selectively bred to be dependent on humans and therefore are unable to exercise their own free will to present themselves to die. The animals have no control over their lives. This shift from human-animal relations based on trust to those based on domination necessitated seeing animals as objects rather than as subjects worthy of respect. Ingold observes that, "Domestication can be said to exist when living animals are integrated as objects into the socio-economic organisation of the human group" (1994: 6). Thus, the advent of domestication of animals was dependent not just on biology but also on culture. Biology enabled us to adopt artificial selective breeding techniques to modify animals into what we wanted and culture enabled us to own the animals as property through the development of law and government. Arluke has explored the conflict in the treatment of animals in

\footnotetext{
${ }^{2}$ In 2017, 24\% of households in the UK owned a dog compared to $17 \%$ of households with a cat. The total population of pet dogs was 8.5 million dogs compared to 8 million cats. Pet Food Manufacturers' Association (PFMA) survey, 2017. https://www.pfma.org.uk/pet-population-2017. Accessed 4th January 2018.
} 
contemporary society - the fact that we shower our pets with love and treat them as one of the family but exploit and kill other domestic animals as utilitarian objects. He observes that "As with any cultural contradiction, these attitudes are built into the normative order, itself perpetuated by institutions that provide ways out of contradictions by supplying myths to bridge them and techniques to assuage troubled feelings" (Arluke 1994: 145). Thus our legal institutions, that objectify animals as property on a par with inanimate things, serve to justify our use of animals and relieve any associated guilt.

The problem is that the law applies the same legal status to animals in two very different situations. Our relationship with farm animals is based on domination but our relationship with companion animals is based on trust. Interestingly, Medieval England recognised this distinction and was fearful of it. During the witch hunts of the sixteenth and seventeenth centuries, legislation was passed in England creating the crime of 'necromancy' and the concept of a witch's familiar was introduced (Hole 1977). In many of the witchcraft cases brought to trial in England, the accused was implicated by keeping companion animals (Serpell 1996). Cohen's study of the medieval perception of animals demonstrates the importance attached to humanity's separation and distance from animals. She notes how "The search for perfect humanity consisted in distancing oneself as far as possible from the animal [world]" (1994: 61). Due to the popularity of this view at the time of the witchcraft hunts, the closeness of the relationship between the human and their companion animal offended society. Serpell observes that "it was claimed that people were debased or dehumanized by the act of co-habiting on such egalitarian and intimate terms with animals" (1994: 134). A relationship with domestic animals based on domination and superiority was acceptable, for example, keeping pigs for meat, but a relationship with a domestic animal, such as a cat living in the home, based on trust and equality was perceived as dangerous and consequently demonised.

Clearly, we have moved a long way from the medieval witch hunts and their antiquated laws. Nowadays, many people share their homes with companion animals even their most personal and private spaces, such as their bedrooms and their beds. Yet whilst medieval laws at least appeared to recognise a distinction between the different relationships we had with animals based on domination or trust, the current laws show a distinct inability to differentiate these. The failure to acknowledge the close and unique bond some humans have with their companion animals is damaging to both humans and animals. The traumatic experience in 2017 of an 87-year old man having to leave his secure home in order to keep his beloved companion dog illustrates the need for urgent change.

\section{The Benefits of the Human-Companion Animal Relationship to Individuals and Society}

There are many disadvantages for those individuals living with a companion animal including the significant financial costs of food, veterinary care and insurance; time spent caring for the animal which can be significant especially for dogs; cleaning up after the animal; concern arising from their destructive or anti-social behaviour; 
emotional distress when the animal is ill or dies; risks of bites, allergic reactions or other illnesses carried by the animal (Plaut et al. 1996). Companion animals provide no economic benefit, so given the significant disadvantages associated with them, what motivates people to acquire and keep a companion animal?

\section{Developing Social Relationships Through Living with a Companion Animal}

Obtaining a companion animal provides an opportunity to form a new social relationship and is a means of extending a person's network of relationships (Harker et al. 2000; Bonas et al. 2000). Using Weiss' theory of relational provisions (Weiss 1974), Harker et al. examined whether the function of the human-companion animal relationship was in part determined by relational provision available from other social relationships. Weiss identified six categories of relational provision that provide an adequate social life and sense of well-being: Attachment; Social integration; Opportunity for nurturance; Reassurance of worth; a sense of reliable alliance and Obtaining of guidance. Weiss argued that individuals need to maintain a number of different relationships to ensure all the relational provisions are met. Harker's study used a 'pet ownership questionnaire' to examine Network of Relationship Inventory ratings (Furman and Buhrmester 1985) from two groups of adults: those who were seeking to obtain a pet and those who were not. It found that participants seeking to acquire a pet had expectations of positive relationship-like provisions-such as companionship, friendship, affection-which they believed would result from keeping an animal. The study found that "high levels of negative relational provision appear to be associated with the desire to own a pet" (2000: 206). Therefore, negative relational provision-conflict, antagonism and punishment-in human-human relationships may increase dissatisfaction with current life circumstances and acquiring a pet may be one strategy adopted by people to compensate for inadequacies in human-human relationships. However, a study by Bonas et al. which also used a survey based on Furman's Network of Relationships Inventory and Weiss' theory of relational provisions to investigate whether pet ownership can be usefully conceptualized as a social relationship, found no evidence to support the idea that pets are used to 'plug the gap' where social provisions are lacking in human-human relationships; "The idea that pet owners use provisions from pets to compensate for shortcomings in other human relationships does not receive support from this study" (Bonas et al. 2000: 233). Couples and families with children are just as likely to own a pet than single people adding support to the view that pets do not substitute human relationships but complement and augment those relationships (Serpell 1996; Beck and Katcher 1996).

The study on social relationships by Bonas et al. gathered data on the participant's relationship with their immediate human family as well as their relationship with their pets so that the data between the human-human relationship and human-companion animal relationship could be compared. The study found striking similarities in the nature of the relationships which adds "empirical weight to the view that human-pet relationships are similar in nature to human-human relationships and, 
perhaps more specifically, that the supportive aspects of the two kinds of relationships are broadly similar" (Bonas et al. 2000: 219).

Further studies have also used Weiss' conceptual framework of social provision to make sense of the human-companion animal relationship in different population groups especially vulnerable groups such as the elderly (Enders-Slegers 2000) or the homeless (Irvine 2013). Enders-Slegers' study, which examined the bond between the elderly and their companion animals, identified the most important social provision derived from the relationship as 'attachment' followed by the 'opportunity for nurturance' and 'reassurance of worth' (Enders-Slegers 2000). Another study examined the human-companion animal relationship amongst people living with HIV in Australia and found support for the claim that companion animals can benefit an owner's emotional, physical and social life by fulfilling one or more of Weiss's six social provisions for psychological well-being (Hutton 2015). Hutton suggests that "a person's belief in their animal's supportive presence may be sufficient to "buffer" negative life challenges" $(2015,211)$. What is significant, therefore, is how a person perceives their relationship with the animal.

These studies suggest that it is the relationship with the companion animal that motivates people to acquire and keep the animal. This social relationship provides relational provision especially attachment, nurturance and a sense of worth, which contributes to an adequate social life and sense of well-being. The benefits people enjoy as a result of the social relationship with their companion animal outweigh the significant cost of keeping the animal in their home. The reach of these benefits goes beyond the owner and the companion animal; research has demonstrated the "ripple effect" of companion animals on wider neighbourhood interactions and a sense of community (Wood et al. 2007).

\section{The Health Benefits of the Human-Companion Animal Relationship}

Since Friedmann's ground breaking research in 1980 that discovered that pet owners had better survival and recovery rates 1 year after discharge from a coronary unit than non-pet owners (Friedmann et al. 1980), there have been many studies attempting to measure the effects of pet ownership on health (Serpell 1991; Anderson et al. 1992; Friedmann et al. 2000, 2013; Levine et al. 2013). The most recent research is a comprehensive study in Sweden involving 3.4 million people over a 12-year period (Mubanga et al. 2017). The study found that owning a dog lowered the risk of dying from cardiovascular disease, especially for single people who experienced a significant reduction in the risk of death from the disease.

It is likely that it is the relationship people have with their pet that is significant to any physiological and psychological health benefits. It is because we socially construct the relationship as akin to family that the animal can protect our health and well-being. Mubanga's study suggests that the social support that emanates from a close bond with a pet dog is likely to be a factor in reducing the cardiovascular risk as well as the increased physical activity that comes with dog ownership (Mubanga et al. 2017). Mere pet ownership is not sufficient to test the validity of the claim that pets are good for your health. The strength of the bond between the owner and 
the pet, as perceived by the owner, needs to play into the equation (Hutton 2015). Someone who owns a pet but has a distant, functional relationship with the animal is unlikely to reap the relational provision benefits (Weiss 1974) that come from a close human-companion animal relationship.

The growing evidence that the human-companion animal relationship provides physical, mental, emotional and social benefits to individuals is strong but even where the strength of the medical evidence is disputed (Herzog 2011), the individual owner's own perception of the benefits remains significant. Bob initially decided to get a dog because he had suffered a heart attack and a dog was recommended to help him keep active. Whether or not Darcie increased Bob's chances of recovery at the time or decreases the prospect of another heart attack now, is less important to Bob than the close bond that has developed between them. Bob perceives this bond as akin to family and it provides many of the benefits of living with another human, for example, company rather than loneliness and a sense of purpose and responsibility in meeting Darcie's welfare needs. Given that society benefits from the human-companion animal relationship, in the form of healthier, less isolated people with better social networks, it is perplexing that law and social policy do so little to protect the relationship especially in the key area of housing.

\section{Housing Law and Companion Animals}

Our relationship with companion animals exists in the home environment. These animals share our home and form a significant part of our daily life routines. We spend more time with our companion animals than we do with human family members who do not live with us. Therefore, laws that govern housing significantly affect our relationship with companion animals. In the UK there is currently nothing to prevent a landlord including a 'no pets' covenant in a tenancy agreement. Restricting pet ownership in this way affects people from all walks of life as living with a companion animal is not limited by class, gender or ethnicity. However, within the housing arena, the inadequacy of law and social policy to protect the human-companion animal relationship, implicates class, disadvantaging those unable to afford to own their home. People on low incomes or those who are reliant on state benefits or are homeless, have fewer choices about where they live and are consequently subject to the whim of the property owner as to whether or not they can keep a companion animal in the property.

\section{Vulnerable People Moving into Care Homes or Supported Accommodation}

'No pet' covenants are especially draconian for the elderly and those with mental illness because these are groups of vulnerable people most likely to need to leave their home to move into supported accommodation. If the supported accommodation does not allow them to take their companion animal with them, or there is a change of policy once the person has moved in, as happened with the care home in Scotland where Bob and Darcie lived, the pet owner is left with the difficult choice to either 
relinquish their companion animal or lose their place in the supported accommodation. Given the nature of the close social bond the elderly develop with their companion animals (Enders-Slegers 2000), it is not surprising that the Blue Cross report that its Pet Bereavement Support Service receives calls from elderly owners who suffer grief after being required to give up their pet to move into a care home that has a 'no pet' policy. ${ }^{3}$

A Private Member's Bill in 2010 sought to address this problem in England and Wales. The Care Homes and Sheltered Accommodation (Domestic Pets) Bill 2009-10 received its second reading in the House of Commons in March 2010. This was preceded in 2009 by the Care Homes (Domestic Pets) Bill 2008-2009. Although both Bills enjoyed cross party support, and a consensus in the house, based on the acknowledged health benefits of pets for the elderly, especially as an antidote to loneliness, the progress of the 2010 Bill was halted in its tracks by a general election. The Bill sought to create a legal presumption that pets (of an authorised, non-dangerous, species) should be permitted in care homes and sheltered accommodation for the elderly and disabled unless their exclusion could be justified, for example, the safety of the other residents necessitated an exclusion or the welfare needs of the pet could not be met in the care home. It was unfortunate that the Bill ran out of time because the Secretary of State for Health stated that, "The Government understand and very much share the sentiment behind the Bill, and are sympathetic to its aims... We do not want there to be any ban on pets in care homes or sheltered housing. However ... the parliamentary timetable will not allow the Bill to succeed". 4

The positive reception of the Private Members' Bills in the House of Commons shows there is strong support in England for legislation to allow the elderly to take their companion animals into care homes and sheltered accommodation based on the health benefits pets provide. It is a small step to acknowledge these health benefits for all people. It is not just the elderly who suffer cardiovascular disease, loneliness and depression. It is not just the elderly who face the prospect of having to move from their home to alternative accommodation and cope with the guilt and distress of giving up their companion animal, an integral part of their family. France and Canada illustrate that legislation prohibiting 'no pet' clauses in all residential leases is possible and not difficult to implement.

\section{All Tenants of Residential Property}

Thousands of people each year in the UK face the prospect of giving up their companion animals because they have to move into rental accommodation that prohibit pets. ${ }^{5}$ Pet owners face a restrictive choice of properties, which can lead to

\footnotetext{
3 The Blue Cross 'Care home pet policies'. https://www.bluecross.org.uk/carehomes (accessed 24 November 2017).

4 Hansard, 5 Mar 2010: Column 1177.

5 Smith, R. 2011. Pet owners face struggle to find rented accommodation. The Guardian, 27 July 2011 https://www.theguardian.com/money/2011/jul/27/pet-owners-rented-accommodation (accessed 12 January 2018).
} 
them having to rent a less suitable property in respect of location and affordability. Research carried out by the Dogs Trust in 2008 found that $78 \%$ of pet owners experienced difficulties finding a residential rental property that allowed pets and by 2011 their research found that pet owners can take up to seven times longer to rent a home compared to non-pet owners. ${ }^{6}$ Research in Australia over a 10 year period to 2013 identified a risk of increased housing insecurity for pet owners, especially where tenants kept pets without the landlord's knowledge and faced the risk of eviction (Powers 2017).

Ontario, Canada, provides a case study of successful legislation to prohibit 'no pet' covenants in all residential leases. A blanket "no pets" clause in a lease is void under Sect. 14 of the Residential Tenancies Act 2006 which states, "A provision in a tenancy agreement prohibiting the presence of animals in or about the residential complex is void". However, a landlord is permitted to refuse to rent to a person who has a companion animal. ${ }^{7}$ This apparent inconsistency in the law appears to encourage dishonesty on the part of the tenant, or at least a failure to disclose the truth, as it is better for a tenant not to admit to having a companion animal until they have signed the lease. Advertisements for rental properties that specify 'no pets' are not considered discriminatory because pet ownership is not protected under Canadian Human Rights laws. However, the position is different for people with disabilities who live with a service animal such as a guide dog for the blind. A landlord cannot refuse to rent to a person with a service dog unless there are exceptional circumstances that justify the refusal, such as the landlord living in the property and having a certified severe pet allergy.

Once there is a tenancy agreement, the landlord cannot evict the tenant on the ground that he or she has a companion animal living in the property with them. The law allows tenants to keep pets on their property even if there is a 'no pets' covenant in the lease and even if the tenant signed an agreement at the outset that they would not keep a companion animal in the property. However, the tenant's right to keep companion animals is not unfettered. Land law invariably has to balance the conflicting interests of parties so it is not surprising that there are conditions and exceptions. Under s.76 of the Residential Tenancies Act (2006, Part V) the landlord can apply to the Landlord and Tenant Board to evict a tenant with a pet where:

(1) The animal has substantially interfered with the reasonable enjoyment of the residential complex for all usual purposes by the landlord and other tenants; or

(2) The presence of the animal has caused the landlord or another tenant to suffer a serious allergic reaction; or

(3) The animal is of a species or breed that is inherently dangerous to the safety of the landlord or other tenants.

\footnotetext{
6 The Dogs Trust carried out research in 2008 and 2011 using online surveys to support their 'Lets with Pets' campaign, http://letswithpets.org.uk/media/research (accessed 13 November 2017).

7 Social Justice Tribunals Ontario. Landlord and Tenant Board, frequently asked questions. http://www. sjto.gov.on.ca/ltb/faqs/\#faq8 (accessed 16 November 2017).
} 
In respect of grounds (1) and (2), the Board shall only make an order for terminating the tenancy and evicting the tenant if it is satisfied that the animal kept by the tenant caused or contributed to that substantial interference or allergic reaction so the landlord will need to provide evidence of this.

Therefore, a tenant cannot be evicted for keeping a companion animal in their property but could be evicted if that companion animal becomes a nuisance, for example, it causes unreasonable noise disturbances or damage to the property or where the landlord or another tenant has a severe allergic reaction to the animal. What amounts to 'substantial interference' in (1) will depend on the facts of the case but common sense and reasonableness prevail. For example, in respect of noise disturbance, it would be unreasonable to require absolute silence from a pet, so the occasional short period of barking from a dog is expected and neighbours will have to tolerate this as they would a crying baby. However, excessive barking at unsociable hours is likely to constitute a substantial interference with the reasonable enjoyment of the property by the landlord or other tenants and will make a tenant liable to eviction. The Residential Tenancies Act also provides that the commission of an "illegal act" is a ground for any tenant to be evicted. Within this context, an 'illegal act' is a broader concept than a criminal offence. Consequently, failure to abide by animal control by-laws applicable in the local jurisdiction, for example, any licensing or micro-chipping requirements or requirements to pick up dog faeces will constitute an illegal act and thereby constitute a ground for terminating the tenancy.

France was the first country to implement legislation to prohibit 'no pet' covenants in residential leases. It enacted legislation in 1970 stipulating that any prohibition of pets in residential tenancies is deemed to be void (Article 10 of the Law of 9 July 1970). The right of the tenant to be able to keep a companion animal is subject to the requirement that the animal does not cause damage to the property or disturbance to the enjoyment of other occupants (including the landlord). A clause banning dangerous dogs is also permissible. Until recently it was thought that this law only applied to long residential leases, but in February 2011 the French Supreme Court ruled that Article 10 also applies to holiday rental properties so landlords cannot refuse to accept companion animals holidaying with their owners. ${ }^{8}$

\section{Article 8 and the Use of 'No Pet' Covenants in Residential Leases}

Article 8 of the European Convention on Human Rights (Art.8) encompasses a right to respect for a person's family and private life and home. Interference with these rights can be justified in certain circumstances including the protection of the health, rights and freedoms of others. The grounds for interference are wide and the state is afforded a margin of appreciation on the basis that the state authorities are best placed to judge the need for the interference and how it is implemented (Handyside

\footnotetext{
8 Association Union fédérale des consommateurs de l'Isère-Que Choisir v. Association Clévacances Isère-départementale des locations de vacances de 1'Isère et autre. Arrêt n ${ }^{\circ} 109$ du 3 février 2011 (0814.402)_Cour de cassation_-Première chambre civile.
} 
$v U K) .{ }^{9}$ Art. 8 covers family life and private life and whilst there is some overlap between these concepts, family life is a narrower concept. It is arguable that the fact that many owners perceive their pet as part of their family may be enough to bring companion animals within the concept of family life for the purposes of Art. 8 (Fox and Westwood 2017) ${ }^{10}$ but, if not, the broader concept of private life, which encompasses a variety of issues, could be utilised. The European Court of Human Rights has held that respect for private life includes "the right to establish and develop relationships with human beings". ${ }^{11}$ In Botta $v$ Italy, the court stated: "Private life, in the Court's view, includes a person's physical and psychological integrity: the guarantee afforded by Article 8 of the Convention is primarily intended to ensure the development, without outside interference, of the personality of each individual in his relations with other human beings". ${ }^{12}$ Since relations with others fall within private life, it is arguable that a close and meaningful relationship with a companion animal also comes within the scope of this broad concept. Such relationships have been shown to provide physical and mental health benefits as well as building social relationships in a community. On this basis, it is difficult to justify excluding this significant relationship from the protection of Art.8.

There are several ways in which Art. 8 could impact on 'no pet' covenants in residential leases in the UK:

(1) By preventing local authority landlords from implementing a blanket ban on all pets in residential rentals;

(2) By the domestic courts interpreting 'no pet' covenants in leases in the private housing sector as unlawful for being in breach of Art.8 by means of indirect horizontal effect by virtue of the fact that the courts are a public body and must not act in contravention of Art.8;

(3) By encouraging the English and Scottish Parliament to pass legislation to prohibit 'no pet' covenants in all residential leases (whether a public or private landlord) on the basis that such covenants constitute an unreasonable interference with human rights.

\section{Local Authority Landlords Cannot Impose a Blanket Ban on Pets}

Housing law and policy that allow 'no pet' covenants in residential tenancy agreements deny people the very act of living with a companion animal. In Belgium, the courts have held that a clause which prohibits a tenant from keeping a companion animal undermines the tenant's private life contrary to Article 8 of the ECHR (the Convention was approved by domestic law in Belgium in 1955).

\footnotetext{
9 (1979-80) 1 EHRR 737.

${ }^{10}$ Companion Animals as Family Members. 2017. Conference paper at 'Animal Law, Ethics and Legal Education', Liverpool John Moores University, September 2017.

11 Niemietz v Germany (1992) 16 EHRR 97 at para.29.

12 (1998) 26 EHRR 241 at para.32.
} 
This was first established as a principle in a case in $1986^{13}$ and later cases demonstrate that courts will seldom enforce a 'no pet' clause in a lease, especially if a landlord has initially tolerated the presence of a companion animal on the premises but then changes his or her mind. ${ }^{14}$ However, an animal can be excluded where it is justifiable, for example, where the animal causes a nuisance to the landlord or other tenants, causes damage to property or is a dangerous animal. Therefore, a clause prohibiting pets that are dangerous or a nuisance or cause damage is permissible as a justifiable and proportionate interference with the tenant's private life. In 2001 a court terminated a lease where a tenant kept two large dogs on the property in breach of a 'no pets' clause in the lease. ${ }^{15}$ The court accepted that a general ban on keeping companion animals affects the tenant's right of integrity to private and family life under Article 8, but acknowledged that on the facts of the case the landlord had a legitimate reason for prohibiting certain pets. The court took into account the need of the landlord to avoid disputes with other tenants in the property due to the "special circumstances specific to the building". The small size and layout of the property meant that it was unsuitable for two large dogs. Presumably it would have been permissible for the tenant to have kept a rabbit or a hamster.

The doctrine of proportionality is a key consideration in Art.8 cases and requires that the interference is in proportion to the aim to be achieved and does not go further than is needed. Even if it could be argued that the ban on pets in residential tenancies was necessary in a democratic society to protect the health and rights of the other occupants living in close proximity, a blanket ban on all pets is disproportionate to the object to be achieved. Many companion animals have no adverse effects on neighbours, for example, a house rabbit, a hamster, even a well-behaved dog. The current legislation in Canada and France demonstrates that it is possible to have proportionate interference that permits pets to be banned in certain circumstances, for example, if the pet causes a nuisance or a severe allergic reaction.

In England, public authority landlords must not act in violation of Convention rights when fulfilling their role as a landlord (s.6, Human Rights Act 1998). The Supreme Court has held that Art.8 is engaged in possession proceedings where a local authority landlord is seeking to evict a tenant. ${ }^{16}$ If it is accepted that ownership of a companion animal falls within 'family and private life' under Art.8 and that having a blanket ban on all pets in a residential lease is a disproportionate interference with those rights, then the public authority landlord will be acting in contravention of the Convention rights if it enforces the 'no pet' covenant in the lease.

\footnotetext{
13 Civ.Liege, October 21, 1986, J.L.M.B., 1987, 578.

14 Y. Merchiers, Les baux, Le bail en general, Larcier, 1997, p. 210, who quotes Civ. Termonde, February 20th 1989, R.W., 1990-1991, p. 216 and J.P. Lennik, January 25th 1988, R.W., 1989-1990, p. 161.

15 Justice of the Peace of Couvin, 14 June 2001.

16 Manchester CC v Pinnock [2010] UKSC 45, [2011] 2 AC 104.
} 


\section{The Duty of the English Courts as a Public Body to Respect Private Life}

The scope of Art. 8 does not stop with public authority landlords. The case law of the European Court of Human Rights shows that Art.8 imposes positive obligations on states to adopt measures that secure respect for private life even in the sphere of private relations such as between a tenant and a private landlord (Rook 2001). This refers to 'indirect horizontal effect' where legal relations between private parties are indirectly affected by relying on another cause of action-in this case, repossession of let property - as a vehicle by which the Convention rights can have an impact (Clayton and Tomlinson 2009). Under s.6, Human Rights Act 1998 the English court, as a public authority, is required not to act in a way which is incompatible with a Convention right. ${ }^{17}$ There is consequently an argument that if a private landlord seeks a repossession order in an English court, on the basis of a tenant keeping a companion animal in breach of a covenant in the lease prohibiting pets, the court would be able to declare the 'no pets' clause as contrary to Art. 8 and consequently unlawful. Thus, a private landlord would not be able to evict a tenant solely on the basis of their keeping companion animals on the property. Whilst the English courts have been reluctant to apply Art. 8 to possession proceedings between private individuals in the private housing sector, ${ }^{18}$ Ramshaw argues that there are strong reasons for changing this approach. ${ }^{19}$ In respect of 'no pet' covenants, Belgium provides a useful example of how Art. 8 can be used by the domestic courts to prevent a tenant from being evicted for keeping a companion animal but the problem is that this approach doesn't prevent 'no pet' clauses from being included in a lease agreement in the first place. This means that many tenants, unfamiliar with the intricacies of the law, will assume the covenant to be valid and believe they cannot keep a companion animal at the property. If a tenant does introduce a companion animal and the landlord brings an action in court to evict the tenant, it will be up to the court, on a case by case basis to determine whether the tenant can be evicted.

\section{Legislation by Parliament}

There is considerable regulation by the state in the sphere of rentals by private landlords. Laws have often recognised the unequal bargaining strengths between landowners and those seeking to find somewhere to live and have consequently sought to limit the power of landlords to impose unreasonable conditions or restrictions (for example the Rent Act 1977 prohibited unreasonable rents). The need to regulate the power of private landlords is especially significant in the current economic climate of austerity, in which home ownership is declining and rental accommodation is in high demand. Housing is a fundamental human need and society has a responsibility

\footnotetext{
17 Campbell [2004] 2 WLR 1232.

${ }^{18}$ McDonald v McDonald [2016] UKSC 28, [2016] 3 WLR 45; Malik v Fassenfelt [2013] EWCA Civ 798, [2013] 28 EG 84.

${ }^{19}$ Ramshaw, A. The role of Article 8 of the European Convention on Human Rights in public and private sector possession proceedings. $\mathrm{PhD}$ thesis, 2016.
} 
to adopt laws that protect tenants from arbitrarily losing their home. Bob faced eviction because a new manager of the residential care home did not want him to keep his dog, Darcie. No law protects Bob's relationship with Darcie even though for Bob, Darcie is akin to a family member. The decision to own a companion animal and enjoy the health benefits and expansion of social networks that accompanies this decision arguably falls within a person's family and private life under Art.8. Therefore, it is appropriate for the state to pass a law prohibiting 'no pet' covenants in residential leases since a blanket ban on pets constitutes an unreasonable interference with a person's private life.

\section{Conclusion}

In Canada the Law Commission has recognised the need for the state to identify and support a variety of close relationships, especially in the LGBT community (Westwood 2013). Their report recommended, "the state must provide adequate legal structures that support the relationships that citizens develop" (Law Commission of Canada 2001). The Law Commission was not talking about companion animals but nevertheless it is a recognition by an important institution of law reform that the law needs to keep pace with changes in society in how we construct social relationships with 'significant others'. Whether the significant other is a human or a companion animal does not detract from the strength of the bond and its significance to that person. The law's failure to recognise and protect this relationship can put people at risk, for example, owners of companion animals having to leave supported accommodation or taking a lease beyond their financial means or in an unsuitable location just to be able to maintain their relationship with their companion animal.

We already have a precedent for treating animals differently under the law depending on the way we use them and the social category we give them. This legal construct can be invoked to protect our relationship with companion animals. By understanding the origin of the legal status of domestic animals as property, it is possible to differentiate companion animals from other animals. The key to this is to differentiate animals on the basis of our relationship with the animals. It is the nature of the relationship that is significant and not the fact of ownership. Domestic animals are owned by someone whether it is a pig being raised for meat or a dog living in the home and treated as a family member. The concept of ownership is the same in these two examples, but the essential difference is the nature of the human-animal relationship. One is based on domination and the other is based on trust. One is a relationship of ownership in which the pig is used for the benefit of humans regardless of the detrimental effects on its welfare, whereas the other is a social relationship which benefits both the dog and the human and creates a close bond of mutual companionship. The law should recognise this difference and better protect the human-companion animal relationship. Nowhere is this more important than in the housing arena, since restrictions in allowing tenants to keep pets in residential properties denies them the opportunity to extend their social networks by acquiring and maintaining valuable social relationships. The fact that this social relationship is with an animal and not a human is irrelevant as both provide 
benefits to social wellbeing and health. It is here advocated that the human-companion animal relationship falls within the perimeters of 'private life' in Art.8 ECHR and therefore should be respected under English and Scottish law. The best way to ensure this protection is by legislation to prohibit 'no pet' covenants in residential leases in all properties, whether in the public or private housing sector, subject to reasonable exceptions such as the health and wellbeing of other occupants.

\section{Compliance with ethical standards}

Conflict of interest The author states that there is no conflict of interest.

Open Access This article is distributed under the terms of the Creative Commons Attribution 4.0 International License (http://creativecommons.org/licenses/by/4.0/), which permits unrestricted use, distribution, and reproduction in any medium, provided you give appropriate credit to the original author(s) and the source, provide a link to the Creative Commons license, and indicate if changes were made.

\section{References}

Anderson, W.P., C.M. Reid, and G.L. Jennings. 1992. Pet ownership and risk factors for cardiovascular disease. Medical Journal of Australia 157: 298-301.

Arluke, A. 1994. Managing emotions in an animal shelter. In Animals and human society: Changing perspectives, ed. A. Manning and J.A. Serpell, 145-165. London: Routledge.

Beck, A., and A. Katcher. 1996. Between pets and people: The importance of animal companionship. West Lafayette: Purdue University Press.

Bonas, S., J. McNicholas, and G. Collis. 2000. Pets in the network of family relationships: An empirical study. In Companion animals and us: Exploring the relationships between people and pets, ed. A. Podberscek, E. Paul, and J. Serpell, 209-236. Cambridge: Cambridge University Press.

Charles, N., and C. Aull Davies. 2008. My family and other animals: Pets as kin. Sociological Research Online 13(5): 4.

Clayton, R., and H. Tomlinson. 2009. The law of human rights. 2nd ed. Oxford: Oxford University Press.

Clutton-Brock, J. 1994. The unnatural world: Behavioural aspects of humans and animals in the process of domestication. In Animals and human society: Changing perspectives, ed. A. Manning and J.A. Serpell, 23-35. London: Routledge.

Cohen, E. 1994. Animals in medieval perceptions: The image of the ubiquitous other. In Animals and human society: Changing perspectives, ed. A. Manning and J.A. Serpell, 59-80. London: Routledge.

Davis, S.J., and F.R. Valla. 1978. Evidence for the domestication of the dog 12,000 years ago in Natufian of Israel. Nature 276: 608.

DeMello, M. 2012. Animals and society: An introduction to human-animal studies. New York: Columbia University Press.

Enders-Slegers, M. 2000. The meaning of companion animals: Qualitative analysis of the life histories of elderly cat and dog owners. In Companion animals and us: Exploring the relationships between people and pets, ed. A. Podberscek, E. Paul, and J. Serpell, 237-256. Cambridge: Cambridge University Press.

Fox, M., and S. Westwood. 2017. Companion animals as family members. Conference paper. 'Animal Law, Ethics and Legal Education' conference, Liverpool John Moores University.

Franklin, A. 2006. Be[a]ware of the dog: A post-humanist approach to housing. Housing, Theory and Society 23(3): 137-156.

Friedmann, E., A.H. Katcher, J.J. Lynch, and S.A. Thomas. 1980. Animal companions and 1-year survival of patients after discharge from a coronary care unit. Public Health Reports 95: 307-312.

Friedmann, E., S.A. Thomas, and T. Eddy. 2000. Companion animals and human health: Physical and cardiovascular influences. In Companion animals and us: Exploring the relationships between 
people and pets, ed. A. Podberscek, E. Paul, and J. Serpell, 125-142. Cambridge: Cambridge University Press.

Friedmann, E., et al. 2013. Pet's presence and owner's blood pressures during the daily lives of pet owners with pre-to-mild hypertension. Anthrozoos 26(2): 535-550.

Furman, W., and D. Buhrmester. 1985. Children's perceptions of the personal relationships in their social networks. Developmental Psychology 21: 1016-1024.

Harker, R.M., G.M. Collis, and J. McNicholas. 2000. The influence of current relationships upon pet animal acquisition. In Companion animals and us: Exploring the relationships between people and pets, ed. A. Podberscek, E. Paul, and J. Serpell, 189-208. Cambridge: Cambridge University Press.

Herzog, H. 2011. The impact of pets on human health and psychological well-being: Fact, fiction, or hypothesis? Current Directions in Psychological Science 20: 236-239.

Hole, C. 1977. Witchcraft in England. London: Batsford.

Hutton, V. 2015. Social provisions of the human-animal relationship amongst 30 people living with HIV in Australia. Anthrozoos 28(2): 199-214.

Ingold, T. 1994. From trust to domination: An alternative history of human-animal relations. In Animals and human society: Changing perspectives, ed. A. Manning and J.A. Serpell, 1-22. London: Routledge.

Irvine, L. 2013. Animals as lifechangers and lifesavers: Pets in the redemption narratives among homeless people. Journal of Contemporary Ethnography 42(1): 3-30.

Law Commission of Canada. 2001. Beyond conjugality: Recognizing and supporting close personal adult relationships. Ottowa: Law Commission of Canada.

Levine, G.N., et al. 2013. Pet Ownership and cardiovascular risk: A scientific statement from the American Heart Association. Circulation 127: 2353-2363.

Morell, V. 1997. The origin of dogs: Running with the wolves. Science 276: 1647.

Mubanga, M., L. Byberg, C. Nowak, A. Egenvall, P. Magnusson, E. Ingelsson, and T. Fall. 2017. Dog ownership and the risk of cardiovascular disease and death-A nationwide cohort study. Scientific Reports. https://doi.org/10.1038/s41598-017-16118-6.

Plaut, M., E.M. Zimmerman, and R.A. Goldstein. 1996. Health hazards to humans associated with domestic pets. Annual Review of Public Health 17: 221-245.

Power, E. 2017. Renting with pets: A pathway to housing insecurity? Housing Studies 32(3): 336-360.

Rook, D. 2001. Property law and human rights. London: Blackstone Press Ltd.

Rook, D. 2014. Who gets Charlie? The emergence of pet custody disputes in family law: Adapting theoretical tools from Child Law. International Journal of Law, Policy and Family 28: 177-193.

Serpell, J.A. 1991. Beneficial effects of pet ownership on some aspects of human health and behaviour. Journal of the Royal Society of Medicine 84: 717-720.

Serpell, J.A. 1996. In the company of animals. Cambridge: Cambridge University Press.

Serpell, J.A. 2000. Creatures of the unconscious: Companion animals as mediators. In Companion animals and us: Exploring the relationships between people and pets, ed. A. Podberscek, E. Paul, and J. Serpell, 108-124. Cambridge: Cambridge University Press.

Serpell, J.A., and E. Paul. 1994. Pets and the development of positive attitudes to animals. In Animals and human society: Changing perspectives, ed. A. Manning and J.A. Serpell, 127-144. London: Routledge.

Tanner, A. 1979. Bringing home animals: Religious ideology and mode of production of the Mistassini Cree Hunters. London: Hurst Publishers.

Weiss, R. 1974. The provisions of social relationships. In Doing unto others, ed. Z. Rubin, 17-26. Engelwoods Cliffs, NJ: Prentice-Hall.

Weston, K. 1991. Families we choose. New York: Columbia University Press.

Westwood, S. 2013. My friends are my family: An argument about the limitations of contemporary law's recognition of relationships in later life. Journal of Social Welfare and Family Law 35(3): 347-363.

Wolfson, D., and M. Sullivan. 2004. Foxes in the hen house: Animals, agribusiness and the law: A modern American Fable. In Animal rights, ed. C. Sunstein and M. Nussbaum, 205-233. Oxford: Oxford University Press.

Wood, L., B. Giles-Corti, M. Bulsara, and D. Bosch. 2007. More than a furry companion: The ripple effect of companion animals on neighbourhood interactions and sense of community. Society and Animals 15: 43-56. 